\title{
ARTICLE
}

Check for

updates

Cite as

Nano-Micro Lett.

(2019) 11:94

Received: 21 August 2019

Accepted: 14 October 2019

Published online: 31 October 2019

(C) The Author(s) 2019

\section{High-Power and Ultralong-Life Aqueous Zinc-Ion Hybrid Capacitors Based on Pseudocapacitive Charge Storage}

\author{
Liubing Dong ${ }^{1}$, Wang Yang ${ }^{1}$, Wu Yang ${ }^{1}$, Chengyin Wang ${ }^{2}$, Yang $\mathrm{Li}^{3}$, Chengjun $\mathrm{Xu}^{4}{ }^{凶}$, \\ Shuwei $\mathrm{Wan}^{5}$, Fengrong $\mathrm{He}^{5}$, Feiyu Kang ${ }^{4}$, Guoxiu Wang ${ }^{1 凶}$ \\ Liubing Dong and Wang Yang have contributed equally to this work. \\ $\square$ Chengjun Xu, vivaxuchengjun@163.com; Guoxiu Wang, guoxiu.wang@uts.edu.au \\ 1 Centre for Clean Energy Technology, Faculty of Science, University of Technology Sydney, Sydney, \\ NSW 2007, Australia \\ 2 School of Chemistry and Chemical Engineering, Yangzhou University, Yangzhou 225002, \\ People's Republic of China \\ 3 School of Photovoltaic and Renewable Energy Engineering, University of New South Wales, Sydney, \\ NSW 2052, Australia \\ 4 Shenzhen Geim Graphene Center, Tsinghua Shenzhen International Graduate School, Tsinghua University, \\ Shenzhen 518055, People's Republic of China \\ 5 HEC Group Pty Ltd, Canterbury, VIC 3216, Australia
}

\section{HIGHLIGHTS}

- This work starts the research of pseudocapacitive oxide materials for multivalent $\mathrm{Zn}^{2+}$ storage.

- The constructed $\mathrm{RuO}_{2} \cdot \mathrm{H}_{2} \mathrm{O} \| \mathrm{Zn}$ systems exhibit outstanding electrochemical performance, including a high discharge capacity, ultrafast charge/discharge capability, and excellent cycling stability.

- The redox pseudocapacitive behavior of $\mathrm{RuO}_{2} \cdot \mathrm{H}_{2} \mathrm{O}$ for $\mathrm{Zn}^{2+}$ storage is revealed.

ABSTRACT Rechargeable aqueous zinc-ion hybrid capacitors and zincion batteries are promising safe energy storage systems. In this study, amorphous $\mathrm{RuO}_{2} \cdot \mathrm{H}_{2} \mathrm{O}$ for the first time was employed to achieve fast and ultralong-life $\mathrm{Zn}^{2+}$ storage based on a pseudocapacitive storage mechanism. In the $\mathrm{RuO}_{2} \cdot \mathrm{H}_{2} \mathrm{O} \| \mathrm{Zn}$ zinc-ion hybrid capacitors with $\mathrm{Zn}\left(\mathrm{CF}_{3} \mathrm{SO}_{3}\right)_{2}$ aqueous electrolyte, the $\mathrm{RuO}_{2} \cdot \mathrm{H}_{2} \mathrm{O}$ cathode can reversibly store $\mathrm{Zn}^{2+}$ in a voltage window of $0.4-1.6 \mathrm{~V}$ (vs. $\mathrm{Zn} / \mathrm{Zn}^{2+}$ ), delivering a high discharge capacity of $122 \mathrm{mAh} \mathrm{g}^{-1}$. In particular, the zinc-ion hybrid capacitors can be rapidly charged/discharged within $36 \mathrm{~s}$ with a very high power density of $16.74 \mathrm{~kW} \mathrm{~kg}^{-1}$ and a high energy density of $82 \mathrm{Wh} \mathrm{kg}^{-1}$. Besides, the zinc-ion hybrid capacitors demonstrate an ultralong cycle life (over 10,000 charge/discharge cycles). The kinetic analysis elucidates that the ultrafast $\mathrm{Zn}^{2+}$ storage in the $\mathrm{RuO}_{2} \cdot \mathrm{H}_{2} \mathrm{O}$ cathode originates from redox

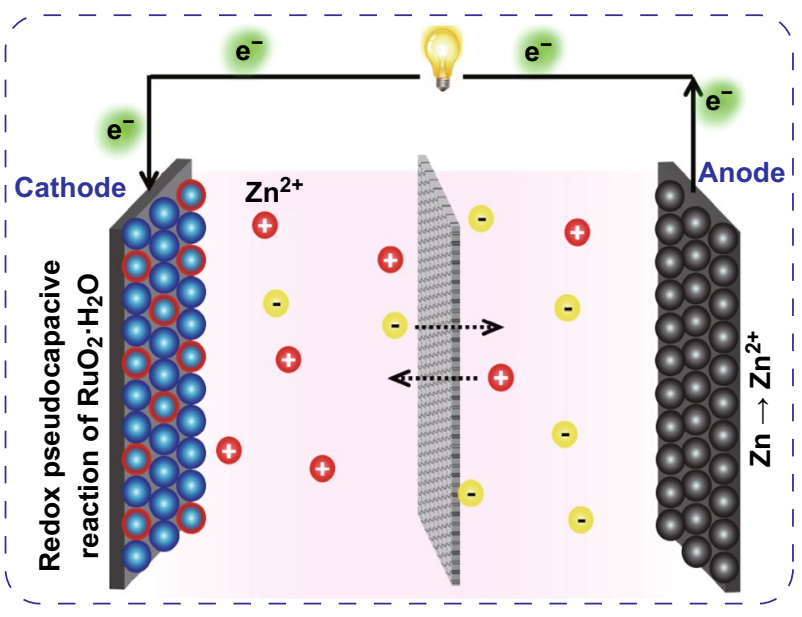
pseudocapacitive reactions. This work could greatly facilitate the development of high-power and safe electrochemical energy storage.

KEYWORDS Zinc-ion hybrid capacitor; Hydrous ruthenium oxide; Ultralong life; Redox pseudocapacitance; High power 


\section{Introduction}

Novel energy storage systems with the merits of high safety, fast charge-discharge capability, and high energy density are highly demanded with the rapid development of electric vehicles and customer electronics. Recently, multivalention (e.g., $\mathrm{Zn}^{2+}, \mathrm{Ca}^{2+}, \mathrm{Mg}^{2+}$, and $\mathrm{Al}^{3+}$ ) storage systems have emerged and exhibited unique electrochemical behaviors [1-6]. During various multivalent-ion storage systems, zinc metal anode-based aqueous rechargeable zinc-ion batteries (ZIBs) and zinc-ion hybrid capacitors (ZICs) are particularly attractive [1, 7-11], due to their high safety, low cost, abundant natural resource of zinc, and unique electrochemical features of zinc metal anodes such as low redox potential of $-0.76 \mathrm{~V}$ (vs. standard hydrogen electrode) and ultrahigh volumetric capacity of $5845 \mathrm{Ah} \mathrm{L}^{-1}$. Furthermore, the high ionic conductivity of aqueous electrolytes such as $\mathrm{ZnSO}_{4}$ solutions in ZIBs and ZICs is beneficial for achieving high power output. The electrochemical properties of ZIBs and ZICs are strongly dependent on the $\mathrm{Zn}^{2+}$-storage behaviors in cathode materials.

Several cathode materials have been developed for ZIBs and ZICs, including manganese oxides, vanadium oxides, Prussian blue analogs, conductive polymers, and carbon materials. $\mathrm{Zn}^{2+}$ insertion/extraction in manganese oxides, especially tunnel-structured $\mathrm{MnO}_{2}$, creates high specific capacities. However, the poor electrical conductivity of manganese oxides and manganese dissolution issues cause unsatisfactory rate performance and poor cycling stability [12-15]. Vanadium oxides possess high capacities and fast kinetics for $\mathrm{Zn}^{2+}$ storage [16-22], whereas their high toxicity impedes their practical applications. Besides, most of the Prussian blue analogs show low capacities of about 50 $\mathrm{mAh} \mathrm{g}^{-1}$ when used as cathode materials for ZIBs [23-26]. Although conductive polymers (e.g., polyaniline and polypyrrole) and carbon materials (e.g., activated carbon, denoted as "AC") generally have a $\mathrm{Zn}^{2+}$-storage capacity of 100-150 $\mathrm{mAh} \mathrm{g}^{-1}$ and better rate performance compared to manganese oxides [11, 27-30], their low density of about $0.3-1 \mathrm{mg} \mathrm{cm}^{-2}$ is unfavorable for the volumetric energy density of corresponding batteries. Therefore, seeking highperformance $\mathrm{Zn}^{2+}$-storage materials is still a big challenge.

Herein, for the first time, we demonstrate that fast, ultralong-life, and safe $\mathrm{Zn}^{2+}$ storage can be realized in amorphous $\mathrm{RuO}_{2} \cdot \mathrm{H}_{2} \mathrm{O}$ cathode materials based on a pseudocapacitive storage mechanism. The constructed $\mathrm{RuO}_{2} \cdot \mathrm{H}_{2} \mathrm{OIIZn} \mathrm{ZICs}$ can reversibly store $\mathrm{Zn}^{2+}$ in a voltage window of $0.4-1.6 \mathrm{~V}$ (vs. $\mathrm{Zn} / \mathrm{Zn}^{2+}$ ), delivering a capacity of about $122 \mathrm{mAh}$ $\mathrm{g}^{-1}$, an excellent rate capability and an ultralong cycle life exceeding 10,000 cycles.

\section{Experimental}

\subsection{Electrochemical Measurements}

Amorphous ruthenium oxide hydrate $\left(\mathrm{RuO}_{2} \cdot x \mathrm{H}_{2} \mathrm{O}\right)$ powder was obtained from Sigma-Aldrich Corporation. To synthesize anhydrous $\mathrm{RuO}_{2}$, the $\mathrm{RuO}_{2} \cdot x \mathrm{H}_{2} \mathrm{O}$ powder was heat-treated in air at $300{ }^{\circ} \mathrm{C}$ for $1 \mathrm{~h}$ with a heating rate of $5{ }^{\circ} \mathrm{C} \mathrm{min}{ }^{-1}$. The amorphous $\mathrm{RuO}_{2} \cdot x \mathrm{H}_{2} \mathrm{O}$ power (or anhydrous $\mathrm{RuO}_{2}$ powder) was mixed with conductive black and polyvinylidene fluoride binder in $\mathrm{N}$-methyl-pyrrolidone solutions, then coated on a stainless steel foil, and finally dried at $100{ }^{\circ} \mathrm{C}$ in vacuum to obtain $\mathrm{RuO}_{2} \cdot x \mathrm{H}_{2} \mathrm{O}\left(\right.$ or $\left.\mathrm{RuO}_{2}\right)$ electrodes. Mass loading of active materials in the prepared cathodes was $2.5-3.0 \mathrm{mg} \mathrm{cm}^{-2}$. Electrochemical performance of these ruthenium oxides for $\mathrm{Zn}^{2+}$ storage was evaluated by assembling CR2032 coin cells, in which $\mathrm{RuO}_{2} \cdot x \mathrm{H}_{2} \mathrm{O}$ (or $\mathrm{RuO}_{2}$ ) electrode was used as the cathode, commercial $\mathrm{Zn}$ foil was used as the anode, air-laid paper was used as separator, and $2 \mathrm{M} \mathrm{Zn}\left(\mathrm{CF}_{3} \mathrm{SO}_{3}\right)_{2}$ or $2 \mathrm{M} \mathrm{ZnSO}_{4}$ aqueous solution served as the electrolyte. Cyclic voltammetry (CV) and electrochemical impedance spectroscopy (EIS) tests were performed on a Bio-Logic VMP3 electrochemical station. An AC amplitude of $5 \mathrm{mV}$ and a frequency range of $0.1-100 \mathrm{kHz}$ were applied for the EIS test at open-circuit voltage (OCV). For galvanostatic charge-discharge (GCD) measurements, when the applied current was $0.1-3 \mathrm{~A} \mathrm{~g} \mathrm{~g}^{-1}$, they were performed on a LAND battery testing instrument, and when the current was 5-20 $\mathrm{A} \mathrm{g}^{-1}$, the GCD measurements were completed on the Bio-Logic VMP3 electrochemical station. (This is because for fast charge/discharge tests, Bio-Logic VMP3 electrochemical station is more sensitive and accurate.)

\subsection{Material and Electrode Characterizations}

We used scanning electron microscopy (SEM; model: Zeiss Supra 55VP) and transmission electron microscopy (TEM; 
model: Tecnai G2 F30) to observe the micromorphologies of samples and used a Brunauer-Emmett-Teller (BET) analyzer to characterize the specific surface area. X-ray diffraction (XRD; model: Bruker D8 Discover Diffractometer) and X-ray photoelectron spectroscopy (XPS; model: MDTCEQ-M20-01) were applied to analyze the phase and compositions. Thermogravimetric (TG)-differential scanning calorimeter was utilized to determine the water content in amorphous $\mathrm{RuO}_{2} \cdot x \mathrm{H}_{2} \mathrm{O}$ powder. Note that to characterize the electrodes at various charge/discharge states, corresponding cells were charged/discharged, then disassembled, and washed using deionized water five times to remove surfaceadsorbed electrolyte.

\section{Results and Discussion}

Figure 1 shows the physicochemical characteristics of the $\mathrm{RuO}_{2} \cdot x \mathrm{H}_{2} \mathrm{O}$ sample. The $\mathrm{RuO}_{2} \cdot x \mathrm{H}_{2} \mathrm{O}$ is irregular-shaped particles with a size of about 100-500 nm (Fig. 1a). Its selected-area electron diffraction (SAED) image (inset in Fig. 1b) exhibits a characteristic halo ring pattern, revealing the amorphous feature of the $\mathrm{RuO}_{2} \cdot x \mathrm{H}_{2} \mathrm{O}$. Correspondingly, the high-resolution TEM image does not show clear lattice fringes (Fig. S1). The amorphous feature of the $\mathrm{RuO}_{2} \cdot x \mathrm{H}_{2} \mathrm{O}$ is also confirmed by the XRD result (Fig. 1c), from which only several broad diffraction peaks are observed. To determine the structural water content in the $\mathrm{RuO}_{2} \cdot x \mathrm{H}_{2} \mathrm{O}$, TG analysis was performed, as shown in Fig. 1d. Mass loss in the temperature range of $100-300{ }^{\circ} \mathrm{C}$ originates from the structural water of the $\mathrm{RuO}_{2} \cdot x \mathrm{H}_{2} \mathrm{O}$ [31], which is $\sim 12.4 \mathrm{wt} \%$. This means that $x$ in the $\mathrm{RuO}_{2} \cdot x \mathrm{H}_{2} \mathrm{O}$ is 1.0. Therefore, the $\mathrm{RuO}_{2} \cdot x \mathrm{H}_{2} \mathrm{O}$ is denoted as $\mathrm{RuO}_{2} \cdot \mathrm{H}_{2} \mathrm{O}$. In the XPS spectrum of $\mathrm{Ru} 3 \mathrm{~d}$ (Fig. 1e), the $\mathrm{Ru} 3 \mathrm{~d}_{3 / 2}$ peak at $285.3 \mathrm{eV}$ and $\mathrm{Ru}$ $3 \mathrm{~d}_{5 / 2}$ peak at $281.1 \mathrm{eV}$ are observed, corresponding well to the previously reported hydrous $\mathrm{RuO}_{2}[32,33]$. Ru 3p XPS spectrum shown in Fig. $\mathrm{S} 2$ provides consistent evidence. $\mathrm{O}$ $1 \mathrm{~s}$ XPS spectrum shown in Fig. If is split into three peaks, proving the coexistence of $\mathrm{Ru}-\mathrm{O}-\mathrm{Ru}$ and $\mathrm{Ru}-\mathrm{O}-\mathrm{H}$ bonds in the amorphous $\mathrm{RuO}_{2} \cdot \mathrm{H}_{2} \mathrm{O}[32,33]$.

The electrochemical performance of the $\mathrm{RuO}_{2} \cdot \mathrm{H}_{2} \mathrm{O}$ for $\mathrm{Zn}^{2+}$ storage was evaluated by assembling the cells with $\mathrm{RuO}_{2} \cdot \mathrm{H}_{2} \mathrm{O}$ cathode, $\mathrm{Zn}$ metal anode, and $\mathrm{Zn}\left(\mathrm{CF}_{3} \mathrm{SO}_{3}\right)_{2}$ aqueous electrolyte. The $\mathrm{RuO}_{2} \cdot \mathrm{H}_{2} \mathrm{O} \| \mathrm{Zn}$ system shows an open-circuit voltage of $1.05 \mathrm{~V}$ and can be reversibly charged/discharged in a voltage window of $0.4-1.6 \mathrm{~V}$ (Fig. 2a). In such a voltage window, the $\mathrm{Zn}\left(\mathrm{CF}_{3} \mathrm{SO}_{3}\right)_{2}$ and
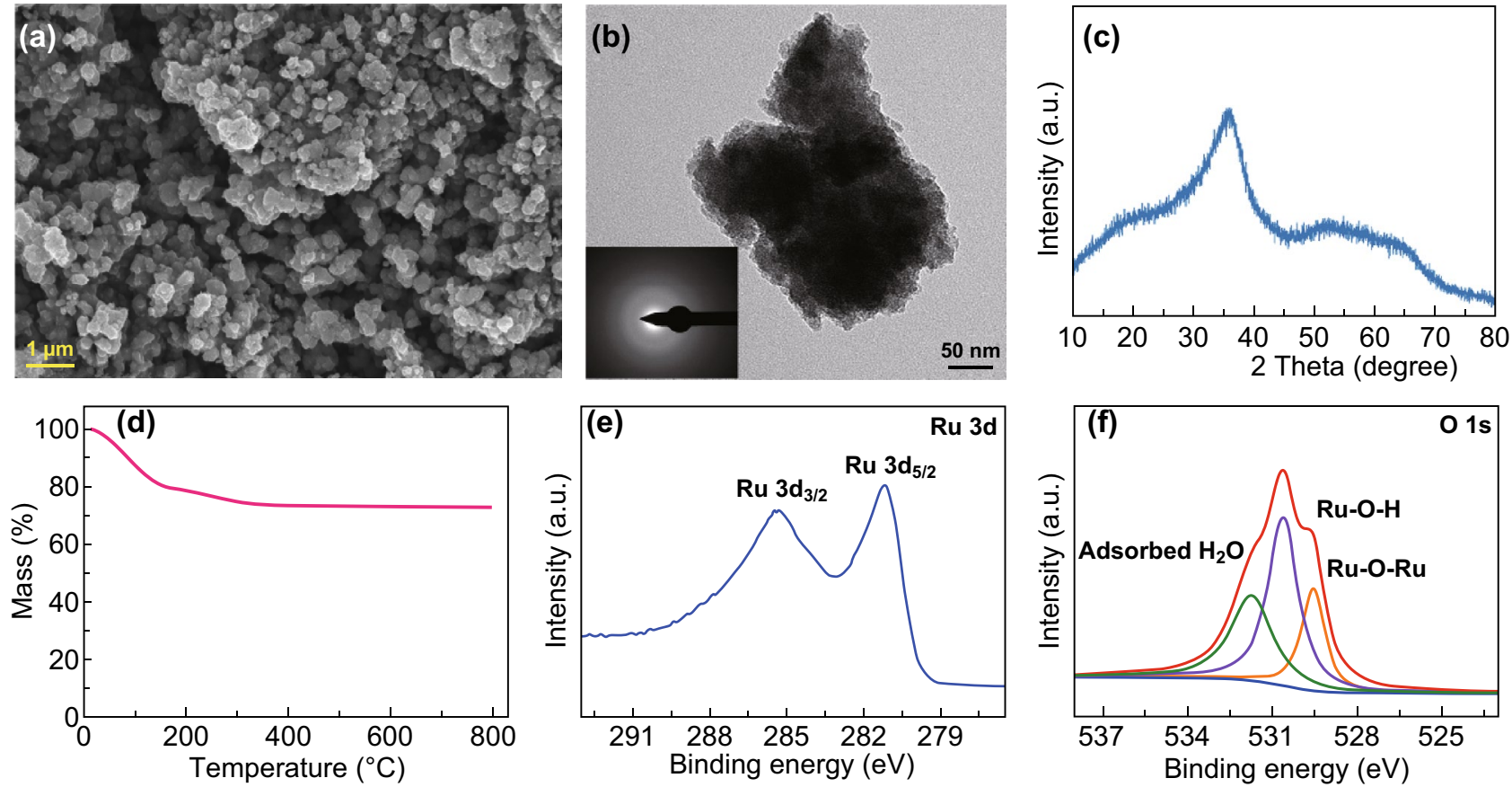

Fig. 1 a SEM image, b TEM image (inset: SAED pattern), c XRD pattern, d TG curve, e Ru 3d, and $\mathbf{f}$ O1 s XPS spectra of the $\mathrm{RuO}_{2} \cdot x \mathrm{H}_{2} \mathrm{O}$ sample 
$\mathrm{ZnSO}_{4}$ aqueous electrolytes are stable and water decomposition does not occur (Fig. S3). In the CV curves, there is one pair of broad redox peaks. Even at high scan rates such as $100 \mathrm{mV} \mathrm{s}^{-1}$, the redox peaks remain, suggesting good rate performance of the $\mathrm{RuO}_{2} \cdot \mathrm{H}_{2} \mathrm{OllZn}$ system. As shown in the GCD profiles (Fig. 2b), the charge curves and discharge curves deviate from linear shapes without flat voltage plateaus. This is consistent with the broad redox peaks observed in the $\mathrm{CV}$ curves. At a charge/discharge current of $0.1 \mathrm{~A} \mathrm{~g}^{1}$, the $\mathrm{RuO}_{2} \cdot \mathrm{H}_{2} \mathrm{O}$ cathode shows a discharge capacity of $122 \mathrm{mAh} \mathrm{g}^{-1}$ with a coulombic efficiency of $86 \%$. When the current increases for 200 times (to $20 \mathrm{~A} \mathrm{~g}^{-1}$ ), in which the $\mathrm{RuO}_{2} \cdot \mathrm{H}_{2} \mathrm{O} \| \mathrm{Zn}$ system is charged/discharged within $36 \mathrm{~s}$, the discharge capacity still reaches $98 \mathrm{mAh} \mathrm{g}^{-1}$. In fact, considering that the coulombic efficiency of the $\mathrm{RuO}_{2} \cdot \mathrm{H}_{2} \mathrm{O} \| \mathrm{Zn}$ system at low current densities of $0.1-1 \mathrm{~A} \mathrm{~g}^{-1}$ and high current densities of $3-20 \mathrm{~A} \mathrm{~g}^{-1}$ is $86-98 \%$ and $99-100 \%$, respectively, the $\mathrm{RuO}_{2} \cdot \mathrm{H}_{2} \mathrm{OllZn}$ system is more suitable for fast charging/ discharging. For comparison, rate performance of some typical cathode materials for $\mathrm{Zn}^{2+}$ storage is summarized

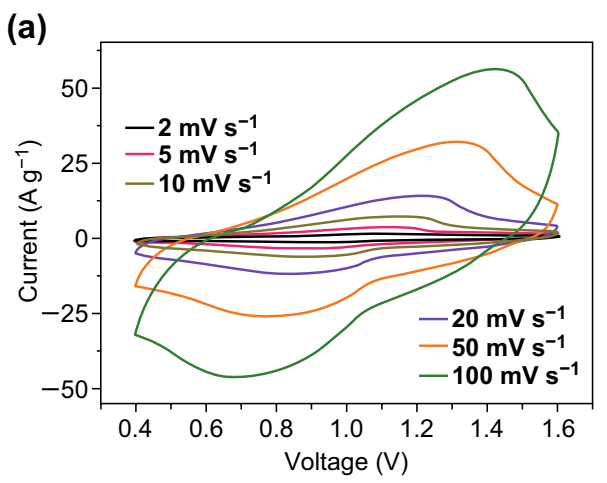

(c)

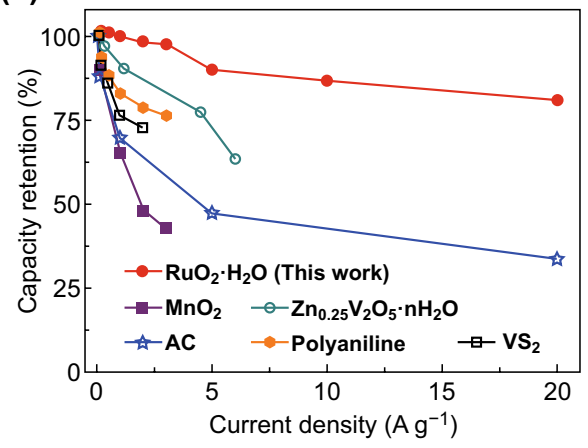

in Fig. 2c, including $\mathrm{MnO}_{2}$ [15], $\mathrm{Zn}_{0.25} \mathrm{~V}_{2} \mathrm{O}_{5} \cdot n \mathrm{H}_{2} \mathrm{O}$ [16], $\mathrm{VS}_{2}$ [34], polyaniline [28], and AC [11]. Figure 2c intuitively shows the excellent rate capability of the $\mathrm{RuO}_{2} \cdot \mathrm{H}_{2} \mathrm{O}$ cathode, compared with the other cathode materials. It should be noted that the $\mathrm{RuO}_{2} \cdot \mathrm{H}_{2} \mathrm{O}$ exhibits similar superior performance in $2 \mathrm{M} \mathrm{ZnSO}_{4}$ aqueous electrolyte (Fig. $\mathrm{S} 4)$. Furthermore, according to the Ragone plot shown in Fig. 2d, the $\mathrm{RuO}_{2} \cdot \mathrm{H}_{2} \mathrm{O}$ cathode can provide a maximum energy density of $119 \mathrm{Wh} \mathrm{kg}^{-1}$. More importantly, it keeps a high energy density of $82 \mathrm{Wh} \mathrm{kg}^{-1}$ under the condition of delivering an ultrahigh power output of $16.74 \mathrm{~kW} \mathrm{~kg}^{-1}$. Such a high power output with considerable energy density is almost impossible for most of the current electrochemical energy storage systems $[9,16,35]$. For instance, the maximum power density of currently reported lithiumion batteries and aqueous ZIBs is generally smaller than $1-10 \mathrm{~kW} \mathrm{~kg}^{-1}$.

The kinetic analysis was performed to reveal the mechanisms for the superior electrochemical performance of the $\mathrm{RuO}_{2} \cdot \mathrm{H}_{2} \mathrm{O}$ cathode. $\mathrm{Zn}^{2+}$ storage in the $\mathrm{RuO}_{2} \cdot \mathrm{H}_{2} \mathrm{O}$ cathode was firstly confirmed by the high-resolution $\mathrm{Zn}$

(b)

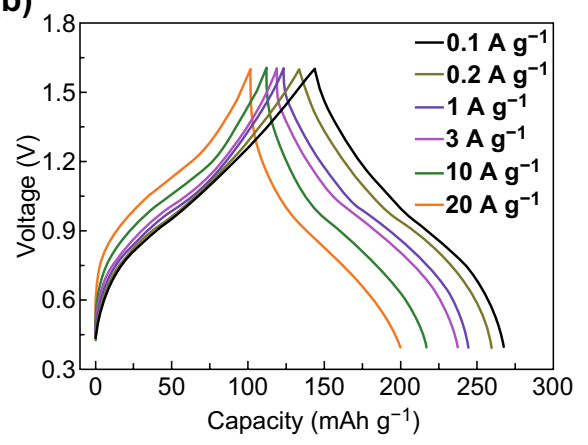

(d)

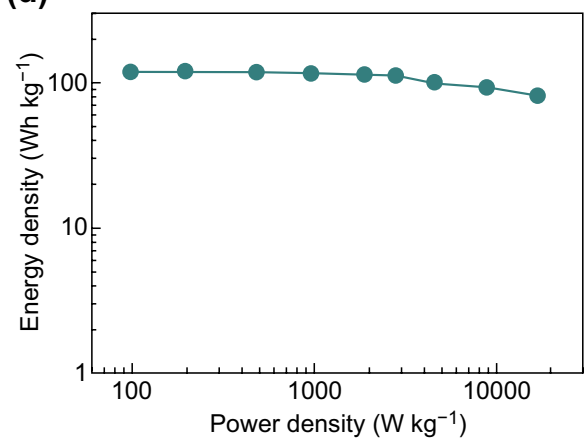

Fig. 2 Electrochemical properties of the $\mathrm{RuO}_{2} \cdot \mathrm{H}_{2} \mathrm{O} \| \mathrm{Zn}$ systems: a CV curves, b GCD profiles, $\mathbf{c}$ rate performance (in comparison with previously reported cathode materials for $\mathrm{Zn}^{2+}$ storage), and $\mathbf{d}$ Ragone plot 
2p XPS spectra shown in Fig. 3. $\mathrm{Zn}^{2+}$ ions were stored in the $\mathrm{RuO}_{2} \cdot \mathrm{H}_{2} \mathrm{O}$ cathode when the cathode was discharged from pristine state to $0.4 \mathrm{~V}$, and almost all $\mathrm{Zn}^{2+}$ ions were extracted from the $\mathrm{RuO}_{2} \cdot \mathrm{H}_{2} \mathrm{O}$ cathode when the cathode was further charged to $1.6 \mathrm{~V}$, implying highly reversible $\mathrm{Zn}^{2+}$ storage in the $\mathrm{RuO}_{2} \cdot \mathrm{H}_{2} \mathrm{O}$ cathode. Besides, $\mathrm{H}^{+}$from the slightly acid $\mathrm{Zn}\left(\mathrm{CF}_{3} \mathrm{SO}_{3}\right)_{2}$ aqueous electrolyte is also proved to participate in the electrochemical reactions in the $\mathrm{RuO}_{2} \cdot \mathrm{H}_{2} \mathrm{O} / / \mathrm{Zn}$ system and contributes to a small capacity

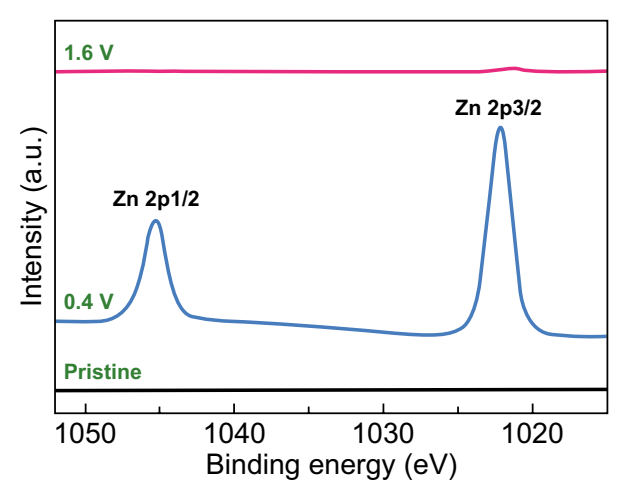

Fig. 3 High-resolution $\mathrm{Zn} 2 \mathrm{p}$ XPS spectra of the $\mathrm{RuO}_{2} \cdot \mathrm{H}_{2} \mathrm{O}$ cathode at various states to the $\mathrm{RuO}_{2} \cdot \mathrm{H}_{2} \mathrm{O}$ cathode (Figs. S5-S7). For the CV curves at various scan rates of the $\mathrm{RuO}_{2} \cdot \mathrm{H}_{2} \mathrm{O} / \mathrm{Zn}$ system (Fig. 2a), the relationship between their peak current $(i)$ and scan rate (v) can be depicted through Eq. 1 [36]:

$i=a v^{b}$,

where $a$ and $b$ are variable parameters. Particularly, $b$ values of 0.5 and 1.0 represent a diffusion-controlled process and a complete capacitive process, respectively [33]. As shown in Fig. $4 \mathrm{a}$, the $b$ values for the anodic peaks and cathodic peaks are close to 1.0, suggesting that $\mathrm{Zn}^{2+}$ storage in the $\mathrm{RuO}_{2} \cdot \mathrm{H}_{2} \mathrm{O}$ cathode is dominated by a capacitive process.

We further tested CV curves at low scan rates (Fig. 4b). At $0.2-1 \mathrm{mV} \mathrm{s}^{-1}$, the voltage separation between anodic peaks and cathodic peaks is very small $(<0.08 \mathrm{~V})$, which is a typical feature of pseudocapacitive behavior [37]. As a comparison, ZIB cathode materials such as $\mathrm{MnO}_{2}$ generally possess a large voltage separation (>0.3 V; Fig. S8). Furthermore, two capacitance differentiation methods were applied to analyze the pseudocapacitive reaction of the $\mathrm{RuO}_{2} \cdot \mathrm{H}_{2} \mathrm{O}$ for $\mathrm{Zn}^{2+}$ storage. According to Dunn's method (Fig. 4c, d) [37], 79.0-96.4\% capacitance originates from the surfacecontrolled capacitive process, i.e., redox pseudocapacitance
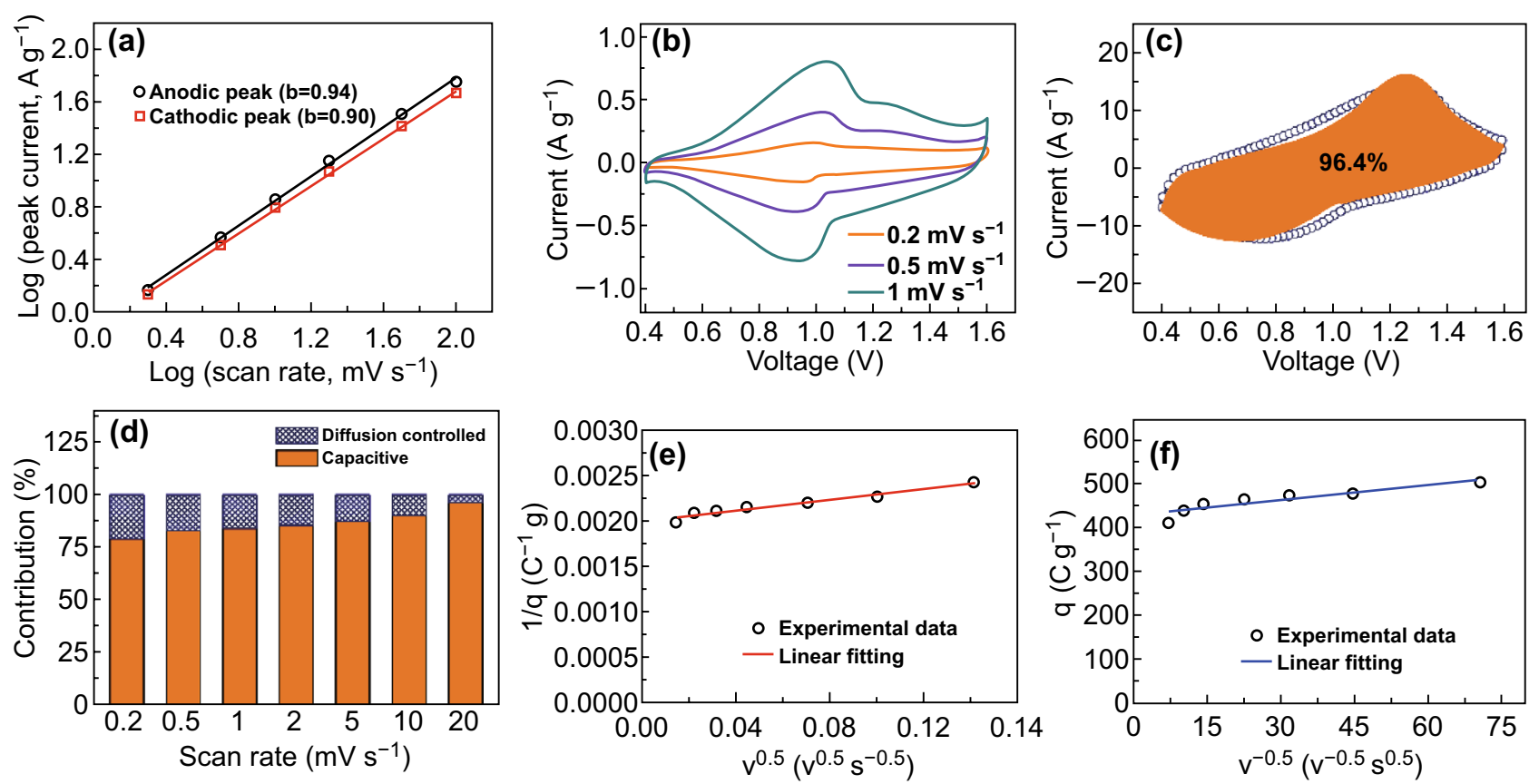

Fig. 4 Kinetic analysis of $\mathrm{Zn}^{2+}$ storage in the $\mathrm{RuO}_{2} \cdot \mathrm{H}_{2} \mathrm{O}$ : a relationship curve of peak current versus scan rate, $\mathbf{b} \mathrm{CV}$ curves at low scan rates of $0.2-1 \mathrm{mV} \mathrm{s}^{-1}$, c capacitive contribution (orange region) to the total current at $20 \mathrm{mV} \mathrm{s}^{-1}$, $\mathbf{d}$ summary of the contribution ratios of capacitive capacity and diffusion-controlled capacity, e, f capacitive contribution analyzed through Trasatti's method, in which $q$ and $v$ are charge stored and scan rate, respectively 
and electric double-layer capacitance. Considering that the specific surface area of the $\mathrm{RuO}_{2} \cdot \mathrm{H}_{2} \mathrm{O}$ is only $57 \mathrm{~m}^{2} \mathrm{~g}^{-1}$ (Fig. S9), the majority of the capacitance is redox pseudocapacitance, while the electric double-layer capacitance accounts a small fraction. Trasatti's method analysis in Fig. 4e, $\mathrm{f}$ points out that the maximum charge that can be stored in the $\mathrm{RuO}_{2} \cdot \mathrm{H}_{2} \mathrm{O}$ and the charge stored at the so-called outer surface (easily accessible to electrolyte ions) of the $\mathrm{RuO}_{2} \cdot \mathrm{H}_{2} \mathrm{O}$ are 502.5 and $428.4 \mathrm{C} \mathrm{g}^{-1}$, respectively [38]. This means that 85.3\% capacity is from the outer surface, which is consistent with the Dunn's method analysis. Such an energy storage mechanism of redox pseudocapacitive behavior, as well as high conductivity of hydrous ruthenium oxides (higher than $100 \mathrm{~S} \mathrm{~cm}^{-1}$ ) [31], benefits for the ultrafast charging/ discharging of the $\mathrm{RuO}_{2} \cdot \mathrm{H}_{2} \mathrm{O}$ cathode [37].

It should be emphasized that the structural water in the $\mathrm{RuO}_{2} \cdot \mathrm{H}_{2} \mathrm{O}$ plays a vital role in $\mathrm{Zn}^{2+}$ storage. As a comparison, anhydrous $\mathrm{RuO}_{2}$ sample was synthesized by heat-treating the $\mathrm{RuO}_{2} \cdot \mathrm{H}_{2} \mathrm{O}$ in air (Figs. 5a, b and S10). The TG curve confirms that after heat treatment, structural water content of the sample is negligible. As for the anhydrous $\mathrm{RuO}_{2}$, its redox pseudocapacitive reactions are notably suppressed, corresponding to very low $\mathrm{Zn}^{2+}$-storage capacities of 38-15
$\mathrm{mAh} \mathrm{g}^{-1}$ at $0.1-20 \mathrm{~A} \mathrm{~g}^{-1}$ (Figs. 5c, d and S11, S12), even though anhydrous $\mathrm{RuO}_{2}$ generally possesses a higher electrical conductivity than hydrous $\mathrm{RuO}_{2} \cdot x \mathrm{H}_{2} \mathrm{O}$ [31]. This is because the structural water can facilitate rapid ion transport in the $\mathrm{RuO}_{2} \cdot \mathrm{H}_{2} \mathrm{O}$ [34]. Similarly, hydrous ruthenium oxides perform much better than anhydrous $\mathrm{RuO}_{2}$ in supercapacitors with $\mathrm{H}_{2} \mathrm{SO}_{4}$ aqueous electrolytes [31].

Besides the excellent high rate performance, the amorphous $\mathrm{RuO}_{2} \cdot \mathrm{H}_{2} \mathrm{O}$ cathode also exhibits superior long-term cyclic stability, with an $87.5 \%$ capacity retention over 10,000 charge/discharge cycles (Fig. 6a). Meanwhile, the coulombic efficiency always maintains $\sim 100 \%$ during the cycling test (except for the initial tens of cycles). Nyquist plots in Fig. 6b of the $\mathrm{RuO}_{2} \cdot \mathrm{H}_{2} \mathrm{O} \| \mathrm{Zn}$ hybrid capacitor reveal a small chargetransfer resistance even after the 10,000 charge/discharge cycles. In addition, the long-term cycling test does not cause an obvious change in the phase composition and micromorphology of the amorphous $\mathrm{RuO}_{2} \cdot \mathrm{H}_{2} \mathrm{O}$ cathode (Fig. $6 \mathrm{c}$ and S13). These imply the high electrochemical and structural stability of the $\mathrm{RuO}_{2} \cdot \mathrm{H}_{2} \mathrm{O}$ cathode during repeated $\mathrm{Zn}^{2+}$ storage processes.
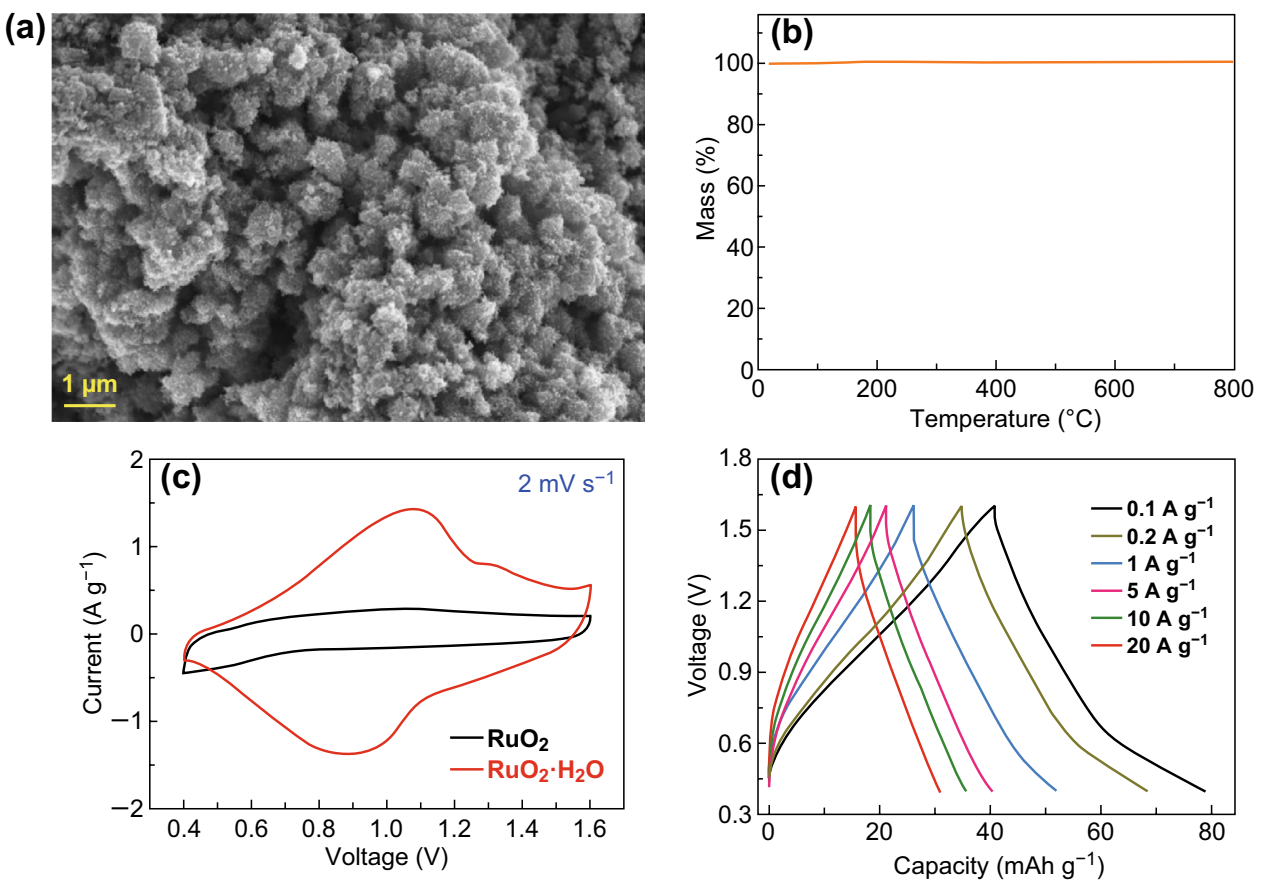

Fig. 5 a SEM image and b TG curve of the anhydrous $\mathrm{RuO}_{2}$ sample. Electrochemical behaviors of the anhydrous $\mathrm{RuO}_{2} \| \mathrm{Zn}$ system with $2 \mathrm{M}$ $\mathrm{Zn}\left(\mathrm{CF}_{3} \mathrm{SO}_{3}\right)_{2}$ aqueous electrolyte: $\mathbf{c} \mathrm{CV}$ curve (in comparison with that of $\mathrm{RuO}_{2} \cdot \mathrm{H}_{2} \mathrm{O} \| \mathrm{Zn}$ system) and $\mathbf{d}$ GCD profiles at $0.1-20 \mathrm{~A} \mathrm{~g}^{-1}$ 

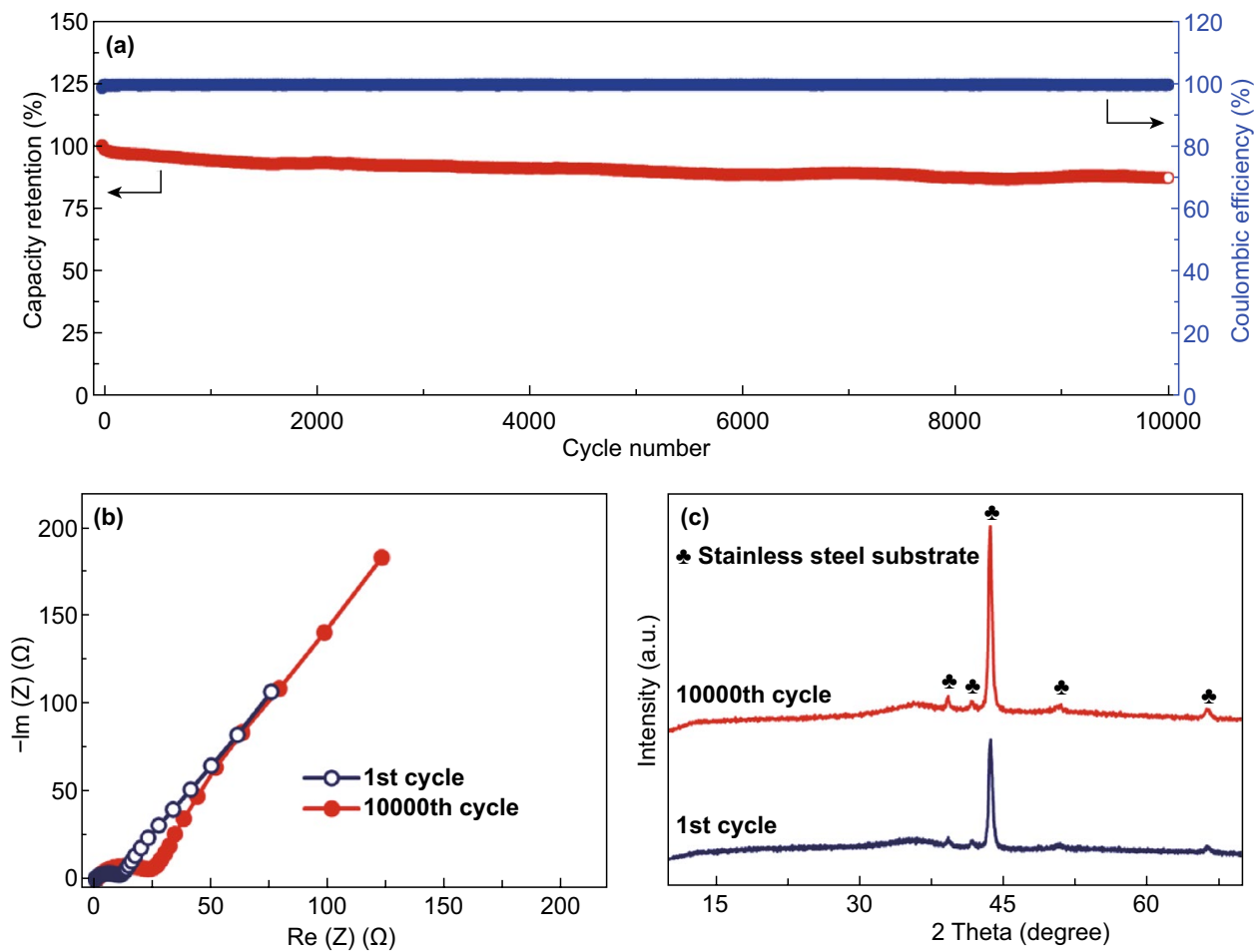

Fig. 6 a Cycling stability test at $20 \mathrm{~A} \mathrm{~g}^{-1}$ of the $\mathrm{RuO}_{2} \cdot \mathrm{H}_{2} \mathrm{O} \| \mathrm{Zn}$ system. b Nyquist plots and c XRD patterns of the $\mathrm{RuO}_{2} \cdot \mathrm{H}_{2} \mathrm{O}$ cathode before and after the cycling test

\section{Conclusions}

In summary, amorphous $\mathrm{RuO}_{2} \cdot \mathrm{H}_{2} \mathrm{O}$ was employed to achieve fast, ultralong-life, and safe $\mathrm{Zn}^{2+}$ storage. In the $\mathrm{RuO}_{2} \cdot \mathrm{H}_{2} \mathrm{O} \| \mathrm{Zn}$ zinc-ion hybrid capacitors with aqueous $\mathrm{Zn}\left(\mathrm{CF}_{3} \mathrm{SO}_{3}\right)_{2}$ electrolyte, the $\mathrm{RuO}_{2} \cdot \mathrm{H}_{2} \mathrm{O}$ cathode reversibly stores $\mathrm{Zn}^{2+}$ in a voltage window of $0.4-1.6 \mathrm{~V}$ (vs. $\mathrm{Zn} /$ $\mathrm{Zn}^{2+}$ ), displaying a discharge capacity of $122 \mathrm{mAh} \mathrm{g}^{-1}$ and an outstanding high rate performance. The zinc-ion hybrid capacitors can be rapidly charged/discharged within $36 \mathrm{~s}$, in which case a very high power density of $16.74 \mathrm{~kW} \mathrm{~kg}^{-1}$ and a high energy density of $82 \mathrm{Wh} \mathrm{kg}^{-1}$ are delivered. Such an excellent high rate performance originates from redox pseudocapacitive reactions of the $\mathrm{RuO}_{2} \cdot \mathrm{H}_{2} \mathrm{O}$ by storing $\mathrm{Zn}^{2+}$. Besides, the zinc-ion hybrid capacitors exhibit superior cycling stability with $87.5 \%$ capacity retention over 10,000 charge/discharge cycles. This work could greatly facilitate the development of ultrafast and safe aqueous electrolytebased electrochemical energy storage.

Acknowledgements The authors acknowledge the financial support by the Australian Research Council through the ARC
Discovery projects (DP160104340 and DP170100436) and Rail Manufacturing Cooperative Research Centre (RMCRC 1.1.1 and RMCRC 1.1.2 projects). This work was also financially supported by the International Science \& Technology Cooperation Program of China (No. 2016YFE0102200) and Shenzhen Technical Plan Project (No. JCYJ20160301154114273).

Open Access This article is distributed under the terms of the Creative Commons Attribution 4.0 International License (http:// creativecommons.org/licenses/by/4.0/), which permits unrestricted use, distribution, and reproduction in any medium, provided you give appropriate credit to the original author(s) and the source, provide a link to the Creative Commons license, and indicate if changes were made.

Electronic supplementary material The online version of this article (https://doi.org/10.1007/s40820-019-0328-3) contains supplementary material, which is available to authorized users.

\section{References}

1. C. Xu, B. Li, H. Du, F. Kang, Energetic zinc ion chemistry: the rechargeable zinc ion battery. Angew. Chem. Int. Ed. 51(4), 933-935 (2012). https://doi.org/10.1002/anie.201106307 
2. O. Chusid, Y. Gofer, H. Gizbar, Y. Vestfrid, E. Levi, D. Aurbach, I. Riech, Solid-state rechargeable magnesium batteries. Adv. Mater. 15(7-8), 627-630 (2003). https://doi. org/10.1002/adma.200304415

3. A.L. Lipson, B. Pan, S.H. Lapidus, C. Liao, J.T. Vaughey, B.J. Ingram, Rechargeable Ca-ion batteries: a new energy storage system. Chem. Mater. 27(24), 8442-8447 (2015). https://doi.org/10.1021/acs.chemmater.5b04027

4. M. Wang, C. Jiang, S. Zhang, X. Song, Y. Tang, H.M. Cheng, Reversible calcium alloying enables a practical room-temperature rechargeable calcium-ion battery with a high discharge voltage. Nat. Chem. 10, 667-672 (2018). https://doi.org/10.1038/s41557-018-0045-4

5. N. Jayaprakash, S.K. Das, L.A. Archer, The rechargeable aluminum-ion battery. Chem. Commun. 47, 12610-12612 (2011). https://doi.org/10.1039/C1CC15779E

6. M.C. Lin, M. Gong, B. Lu, Y. Wu, D.Y. Wang et al., An ultrafast rechargeable aluminium-ion battery. Nature 520, 324-328 (2015). https://doi.org/10.1038/nature14340

7. L. Dong, W. Yang, W. Yang, Y. Li, W. Wu, G. Wang, Multivalent metal ion hybrid capacitors: a review with a focus on zinc-ion hybrid capacitors. J. Mater. Chem. A 7, 1381013832 (2019). https://doi.org/10.1039/C9TA02678A

8. J. Ming, J. Guo, C. Xia, W. Wang, H.N. Alshareef, Zinc-ion batteries: materials, mechanisms, and applications. Mater. Sci. Eng. R 135, 58-84 (2019). https://doi.org/10.1016/j. mser.2018.10.002

9. M. Song, H. Tan, D. Chao, H.J. Fan, Recent advances in Zn-ion batteries. Adv. Funct. Mater. 28, 1802564 (2018). https://doi.org/10.1002/adfm.201802564

10. G. Fang, J. Zhou, A. Pan, S. Liang, Recent advances in aqueous zinc-ion batteries. ACS Energy Lett. 3, 2480-2501 (2018). https://doi.org/10.1021/acsenergylett.8b01426

11. L. Dong, X. Ma, Y. Li, L. Zhao, W. Liu et al., Extremely safe, high-rate and ultralong-life zinc-ion hybrid supercapacitors. Energy Storage Mater. 13, 96-102 (2018). https:// doi.org/10.1016/j.ensm.2018.01.003

12. M.H. Alfaruqi, V. Mathew, J. Gim, S. Kim, J. Song, J.P. Baboo, S.H. Choi, J. Kim, Electrochemically induced structural transformation in a $\gamma-\mathrm{MnO}_{2}$ cathode of a high capacity zinc-ion battery system. Chem. Mater. 27, 3609-3620 (2015). https://doi.org/10.1021/cm504717p

13. H. Pan, Y. Shao, P. Yan, Y. Cheng, K.S. Han et al., Reversible aqueous zinc/manganese oxide energy storage from conversion reactions. Nat. Energy 1, 16039 (2016). https:// doi.org/10.1038/nenergy.2016.39

14. H. Li, L. Ma, C. Han, Z. Wang, Z. Liu, Z. Tang, C. Zhi, Advanced rechargeable zinc-based batteries: recent progress and future perspectives. Nano Energy 62, 550-587 (2019). https://doi.org/10.1016/j.nanoen.2019.05.059

15. K.W. Nam, H. Kim, J.H. Choi, J.W. Choi, Crystal water for high performance layered manganese oxide cathodes in aqueous rechargeable zinc batteries. Energy Environ. Sci. 12, 1999-2009 (2019). https://doi.org/10.1039/C9EE0 $0718 \mathrm{~K}$
16. D. Kundu, B.D. Adams, V. Duffort, S.H. Vajargah, L.F. Nazar, A high-capacity and long-life aqueous rechargeable zinc battery using a metal oxide intercalation cathode. Nat. Energy 1, 16119 (2016). https://doi.org/10.1038/nener gy.2016.119

17. P. He, Y. Quan, X. Xu, M. Yan, W. Yang, Q. An, L. He, L. Mai, High-performance aqueous zinc-ion battery based on layered $\mathrm{H}_{2} \mathrm{~V}_{3} \mathrm{O}_{8}$ nanowire cathode. Small 13, 1702551 (2017). https://doi.org/10.1002/smll.201702551

18. B. Tang, G. Fang, J. Zhou, L. Wang, Y. Lei et al., Potassium vanadates with stable structure and fast ion diffusion channel as cathode for rechargeable aqueous zinc-ion batteries. Nano Energy 51, 579-587 (2018). https://doi.org/10.1016/j.nanoe n.2018.07.014

19. N. Zhang, Y. Dong, M. Jia, X. Bian, Y. Wang et al., Rechargeable aqueous $\mathrm{Zn}-\mathrm{V}_{2} \mathrm{O}_{5}$ battery with high energy density and long cycle life. ACS Energy Lett. 3, 1366-1372 (2018). https ://doi.org/10.1021/acsenergylett.8b00565

20. Y. Yang, Y. Tang, G. Fang, L. Shan, J. Guo et al., Li ${ }^{+}$intercalated $\mathrm{V}_{2} \mathrm{O}_{5} \cdot n \mathrm{H}_{2} \mathrm{O}$ with enlarged layer spacing and fast ion diffusion as an aqueous zinc-ion battery cathode. Energy Environ. Sci. 11, 3157-3162 (2018). https://doi.org/10.1039/ C8EE01651H

21. W. Zhang, S. Liang, G. Fang, Y. Yang, J. Zhou, Ultra-high mass-loading cathode for aqueous zinc-ion battery based on graphene-wrapped aluminum vanadate nanobelts. NanoMicro Lett. 11, 69 (2019). https://doi.org/10.1007/s4082 0-019-0300-2

22. F. Liu, Z. Chen, G. Fang, Z. Wang, Y. Cai, B. Tang, J. Zhou, $\mathrm{S}$. Liang, $\mathrm{V}_{2} \mathrm{O}_{5}$ nanospheres with mixed vanadium valences as high electrochemically active aqueous zinc-ion battery cathode. Nano-Micro Lett. 11, 25 (2019). https://doi.org/10.1007/ s40820-019-0256-2

23. L. Zhang, L. Chen, X. Zhou, Z. Liu, Towards high-voltage aqueous metal-ion batteries beyond: the zinc/zinc hexacyanoferrate system. Adv. Energy Mater. 5, 1400930 (2015). https:// doi.org/10.1002/aenm.201400930

24. Z. Liu, P. Bertram, F. Endres, Bio-degradable zinc-ion battery based on a prussian blue analogue cathode and a bio-ionic liquid-based electrolyte. J. Solid State Electrochem. 21, 20212027 (2017). https://doi.org/10.1007/s10008-017-3589-0

25. R. Trócoli, F.L. Mantia, An aqueous zinc-ion battery based on copper hexacyanoferrate. Chemsuschem 8, 481-485 (2015). https://doi.org/10.1002/cssc.201403143

26. Z. Jia, B. Wang, Y. Wang, Copper hexacyanoferrate with a well-defined open framework as a positive electrode for aqueous zinc ion batteries. Mater. Chem. Phys. 149-150, 601-606 (2015). https://doi.org/10.1016/j.matchemphys.2014.11.014

27. H.Y. Shi, Y.J. Ye, K. Liu, Y. Song, X. Sun, A long-cycle-life self-doped polyaniline cathode for rechargeable aqueous zinc batteries. Angew. Chem. Int. Ed. 57, 16359 (2018). https://doi. org/10.1002/ange.201808886

28. S. Huang, F. Wan, S. Bi, J. Zhu, Z. Niu, J. Chen, A self-healing integrated all-in-one zinc-ion battery. Angew. Chem. Int. Ed. 58, 4357-4361 (2019). https://doi.org/10.1002/ange.20181 4653 
29. P. Zhang, Y. Li, G. Wang, F. Wang, S. Yang et al., Zn-ion hybrid micro-supercapacitors with ultrahigh areal energy density and long-term durability. Adv. Mater. 31, 1806005 (2018). https://doi.org/10.1002/adma.201806005

30. G. Sun, H. Yang, G. Zhang, J. Gao, X. Jin, Y. Zhao, L. Jiang, L. Qu, A capacity recoverable zinc-ion micro-supercapacitor. Energy Environ. Sci. 11, 3367-3374 (2018). https://doi. org/10.1039/C8EE02567C

31. J.P. Zheng, P.J. Cygan, T.R. Jow, Hydrous ruthenium oxide as an electrode material for electrochemical capacitors. J. Electrochem. Soc. 142, 2699-2703 (1995). https://doi. org/10.1149/1.2050077

32. D. Rochefort, P. Dabo, D. Guay, P.M.A. Sherwood, XPS investigations of thermally prepared $\mathrm{RuO}_{2}$ electrodes in reductive conditions. Electrochim. Acta 48, 4245-4252 (2003). https:// doi.org/10.1016/S0013-4686(03)00611-X

33. D.J. Yun, S. Lee, K. Yong, S.W. Rhee, In situ ultraviolet photoemission spectroscopy measurement of the pentacene- $\mathrm{RuO}_{2} /$ Ti contact energy structure. Appl. Phys. Lett. 97, 073303 (2010). https://doi.org/10.1063/1.3481084
34. P. He, M. Yan, G. Zhang, R. Sun, L. Chen, Q. An, L. Mai, Layered $\mathrm{VS}_{2}$ nanosheet-based aqueous $\mathrm{Zn}$ ion battery cathode. Adv. Energy Mater. 7, 1601920 (2017). https://doi. org/10.1002/aenm.201601920

35. P. Simon, Y. Gogotsi, Materials for electrochemical capacitors. Nat. Mater. 7, 845-854 (2008). https://doi.org/10.1038/nmat2 297

36. J. Wang, J. Polleux, J. Lim, B. Dunn, Pseudocapacitive contributions to electrochemical energy storage in $\mathrm{TiO}_{2}$ (Anatase) nanoparticles. J. Phys. Chem. C 111, 14925-14931 (2007). https://doi.org/10.1021/jp074464w

37. V. Augustyn, P. Simon, B. Dunn, Pseudocapacitive oxide materials for high-rate electrochemical energy storage. Energy Environ. Sci. 7, 1597-1614 (2014). https://doi.org/10.1039/ C3EE44164D

38. S. Ardizzone, G. Fregonara, S. Trasatti, "Inner" and "outer" active surface of $\mathrm{RuO}_{2}$ electrodes. Electrochim. Acta 35, 263267 (1989). https://doi.org/10.1016/0013-4686(90)85068-X 